\title{
POROSITY IN HOT FORMED CAST STEEL
}

\author{
${ }^{1}$ Bernd-Arno BEHRENS, ${ }^{1} J o n a t h a n ~ U R S I N U S,{ }^{1}$ Christoph BÜDENBENDER, ${ }^{1}$ Kai BRUNOTTE, \\ ${ }^{2}$ Florian NÜRNBERGER, ${ }^{2}$ Eugen DEMLER, ${ }^{2} \mathrm{Hans}$ Jürgen MAIER
}

${ }^{1}$ Institut für Umformtechnik und Umformmaschinen (Forming Technology and Machines), Leibniz Universität Hannover, Garbsen, Germany, EU, behrens@ifum.uni-hannover.de, ursinus@ifum.uni-hannover.de, buedenbender@ifum.uni-hannover.de, brunotte@ifum.uni-hannover.de

2Institut für Werkstoffkunde (Materials Science), Leibniz Universität Hannover, Garbsen, Germany, EU, nürnberger@iw.uni-hannover.de, demler@iw.uni-hannover.de, maier@iw.uni-hannover.de

https://doi.org/10.37904/metal.2020.3480

\begin{abstract}
In order to reduce the number of process steps of steel forging processes. and thus also tool wear and process costs, tailored preform geometries can be produced by casting. By only one subsequent forming operation it is possible to improve the casting microstructure, eliminate possible defects and achieve the required mechanical properties. To evaluate the properties of the cast microstructure and the closure of possible casting defects during warm/hot forming, cylindrical steel billets (C45/1.0503) were produced by sand casting and then upset in a hydraulic press. Global plastic strain $\varphi$ was varied between 0.3 and 0.7 while forging temperatures of $600{ }^{\circ} \mathrm{C}$ and $1200^{\circ} \mathrm{C}$ were applied to detect possible temperature effects. Conventional rolled bar material formed under the same conditions was used as a reference. After forming, the specimens were tempered and the mechanical properties were determined by tensile tests (ISO 6892-1) and notch impact tests (similar to ISO 148-1). The microstructures were examined by metallographic analysis while defects were characterised using an optical wide-area 3D measurement system and digital image processing. It could be observed that the ultimate tensile strength of the cast-forged specimens depends on the forming temperature and is about $15 \%$ lower in comparison to the reference material at a forming temperature of $600{ }^{\circ} \mathrm{C}$ and $5 \%$ lower at $1200{ }^{\circ} \mathrm{C}$, respectively. The impact energies show a strong dependence on plastic strain for both, the castforged and reference specimens. The values of the mechanical properties of the reference specimens were higher than those of the cast-forged specimens. These results allow a deeper understanding of the cast-forging of steel and will contribute to the cast-forging design of more complex steel parts.
\end{abstract}

Keywords: Cast-forging, steel, porosity, mechanical properties

\section{INTRODUCTION}

The use of lightweight material-efficient parts is one major strategy to reduce energy consumption and the carbon footprint in the automotive and transport industries [1]. To achieve this, forged high-strength components are used e.g. in powertrains or in suspension systems. To maximise material use and part performance, complex geometries are common, but demand multi-stage forging processes with increased flash volume and correspondingly high tool and material costs [2]. To overcome these disadvantages and to allow an extended design freedom, a combination of casting and forging, called cast-forging, is promising. Cast-forging allows for parts with increased complexity compared to forging; by this means the material properties of the cast preforms can be increased by defect elimination and grain refinement. Cast-forging is already being used for the production of aluminium parts for automotive applications, bikes or other transportations [3]. However, cast-forging of steel, which was first investigated in the 1980s [4], has not yet found industrial application. The use of specifically designed cast preforms promises an energy and material efficient production chain. Recent research deals with the economically viable open-die forging of large steel 
ingots and its mechanisms [5]. Nevertheless, with increasing environmental awareness and legislative efforts, energy and material efficient production via cast-forging might be beneficial in the future. Accordingly, a combined casting and precision forging process considering the evolution of microstructure and mechanical properties throughout the process to identify suited geometries for cast preforms is of current interest.

Hence, the objective of this work is to investigate defect elimination and the microstructure evolution of cast steel cylinders during forming. In particular, insight into the required forging parameters regarding microstructural evolution and mechanical properties is to be gained using the example of the low-alloyed steel C45 (1.0503). In contrast to previous findings concerning the heat-treatable steel 42CrMo4 (1.7225) [6], lower plastic strain values were chosen and the anisotropy of the mechanical properties after forging was considered.

\section{EXPERIMENTAL SETUP}

In a first step, $\mathrm{C} 45$ steel cylinders were produced by sand casting. The cylinders had a diameter of $44 \mathrm{~mm}$ and a height of $75 \mathrm{~mm}$. Numerical simulation with the software MAGMASOFT® was used to develop a casting model with turbulence-free melt flow and thus a defined low number of only small-sized casting defects. The casting model is depicted in Figure 1; it features 8-cylinder models with risers. According to the models, a sand casting mould was created manually. C45 rod material was melted in an induction tilt-pot furnace (Inductotherm). The casting temperature used for the $\mathrm{C} 45$ steel was $1680^{\circ} \mathrm{C}$ and the casting time was $10 \mathrm{~s}$.
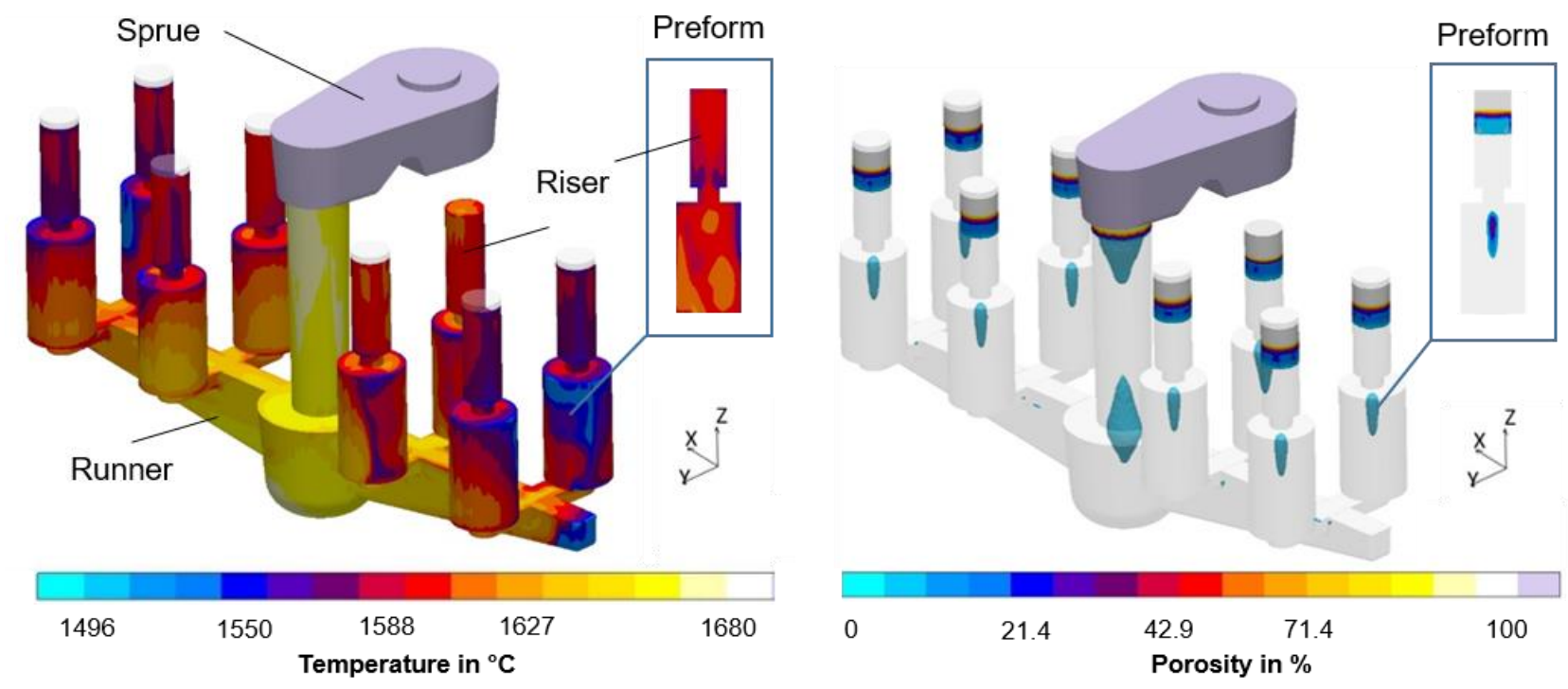

Figure 1 Simulation model of the casting system for casting preforms made of C45. Simulated temperature (left) and porosity (right) directly after filling

After casting and separation from the casting system, the cylinders were heated in a batch furnace to their respective forming temperature and deformed in upsetting experiments. Regarding previous results on cylinders of 42CrMo4 [6], the upsetting stroke was chosen to result in a plastic strain of $\varphi=0.3 ; 0.5 ; 0.7$. Upsetting of the $\mathrm{C} 45$ cylinder was carried out at formig temperatures of $600{ }^{\circ} \mathrm{C}$ (warm forging) and $1200{ }^{\circ} \mathrm{C}$ (hot forging), respectively, on a hydraulic press with a fixed punch velocity of $30 \mathrm{~mm} / \mathrm{s}$. The tools had room temperature and were lubricated with graphite spray (Fuchs Lubritech Con Traer G300). All upsetting experiments were repeated with hot rolled bar material as a reference.

After upsetting, the cylinders were air-cooled and then cut into slices by means of a band saw and ground on a surface grinder to allow optical measurement. The latter was carried out with a wide-area surface scanner (Keyence VR 3200) to detect residual porosity. For each cylinder, two slices were prepared and analysed resulting in six measurements per variant. 
The slices were then further cut into bars as preforms for mechanical testing, as displayed in Figure 2. These bars were similar in size and cross-section and were all commercially quenched and tempered (+QT, according to ISO 683-1) to eliminate the influence of the different heating regimes during upsetting. The heat treatment resulted in a mean Vickers hardness of $244( \pm 23)$ HV 10.

(1)

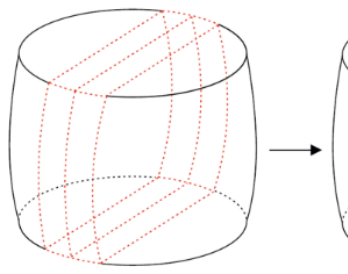

Upset specimens
(2)

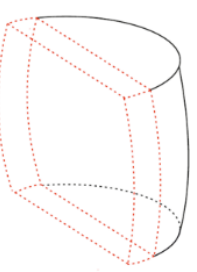

Cut specimens
(3)

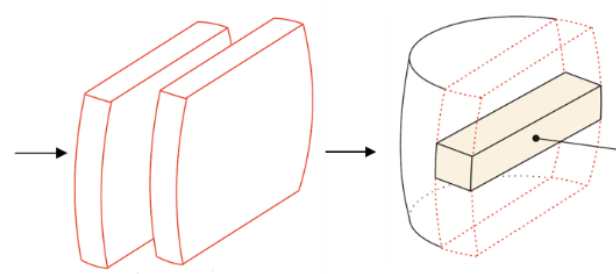

Discs for optical analysis
Horizontal orientation of the preform for mechanical testing

Figure 2 Schematic representation ot the specimen extraction

For tensile testing according to ISO 6892-1, round specimens were manufactured and tested on a universal testing machine (Zwick/Röll Z250). In addition to the tensile tests, notched impact fracture tests were conducted in a way similar to ISO 148-1. Due to the dimensions of the upset cylinders, some specimens $(\varphi=0.3)$ had a reduced length by up to $2 \mathrm{~mm}$ on the unnotched backside. The load-bearing front had the full length. These specimens were tested with a fracture hammer (PSW 750AF). For each variant, three tensile and three impact fracture specimens were manufactured and tested.

As the horizontal plane is not expected to be the weakest, five smaller specimens according to the retracted DIN 50115 were extracted vertically as well as horizontally from specimens upset with $\varphi=0.7$ at $1200{ }^{\circ} \mathrm{C}$. This allowed a direct comparison of the impact energies of these otherwise more unusual geometries (see Figure 3).
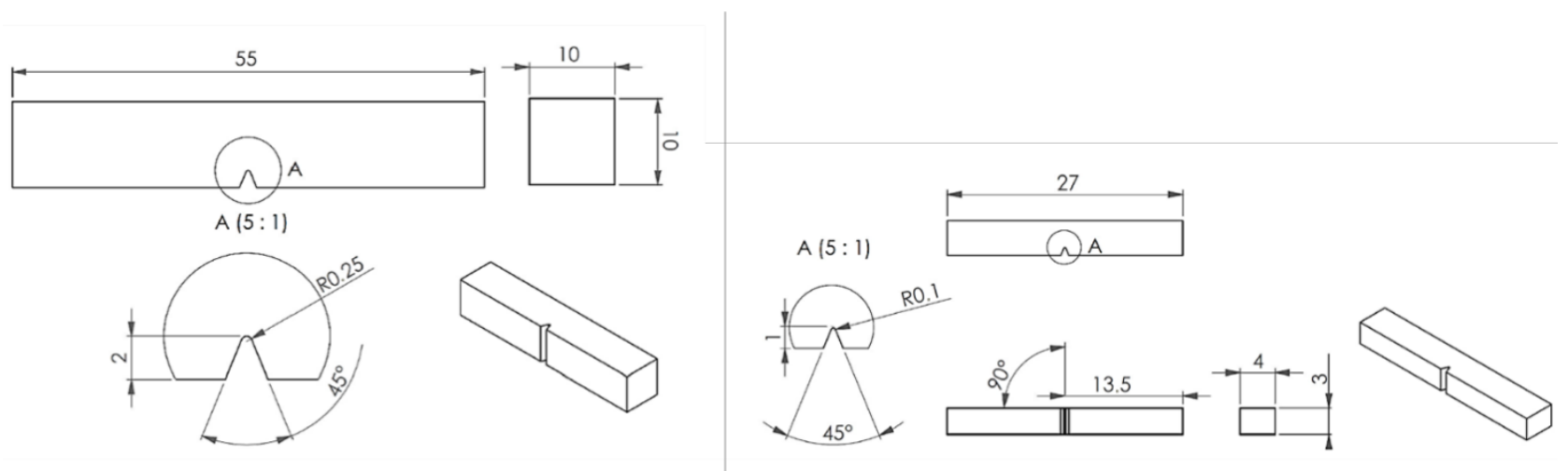

Figure 3 Comparison of the different impact fracture test specimens: ISO 148-1 (left) and DIN 50115 (right)

After etching in a solution of $5 \% \mathrm{HNO}_{3}$, metallographic examination was carried out with a light microscope (Polyvar MET). The chemical composition of the cast-forged and reference specimens after mechanical testing was determined by optical emission spectrometry (OES), with the results given in Table 1.

Table 1 Chemical composition in wt.\% as determined by OES

\begin{tabular}{lcccccccc} 
Elements & $\mathbf{C}$ & $\mathbf{S i}$ & $\mathbf{M n}$ & $\mathbf{P}$ & $\mathbf{S}$ & $\mathbf{C r}$ & Mo & $\mathbf{F e}$ \\
\hline Cast-forged & 0.40 & 0.16 & 0.62 & 0.01 & 0.04 & 0.08 & 0.01 & Bal. \\
\hline Reference & 0.41 & 0.20 & 0.60 & 0.01 & 0.03 & 0.06 & 0.01 & Bal.
\end{tabular}




\section{RESULTS}

The optical surface-scanning images were converted into greyscale values and divided into a grid of cells, for which a mean porosity value was calculated. This allowed a quantitative comparison of the scans and the calculation of a mean porosity distribution over all six surfaces per variant. As seen in Figure 4, low plastic strain and low forging temperatures result in the highest residual pore volume. The pores are concentrated near the top centre of the specimens. With higher deformation, the macroscopic porosity is reduced and the remaining defects are located in regions of low local plastic strain. In each case, the higher forming temperature leads to a reduced defect volume when compared to the low temperature variant.

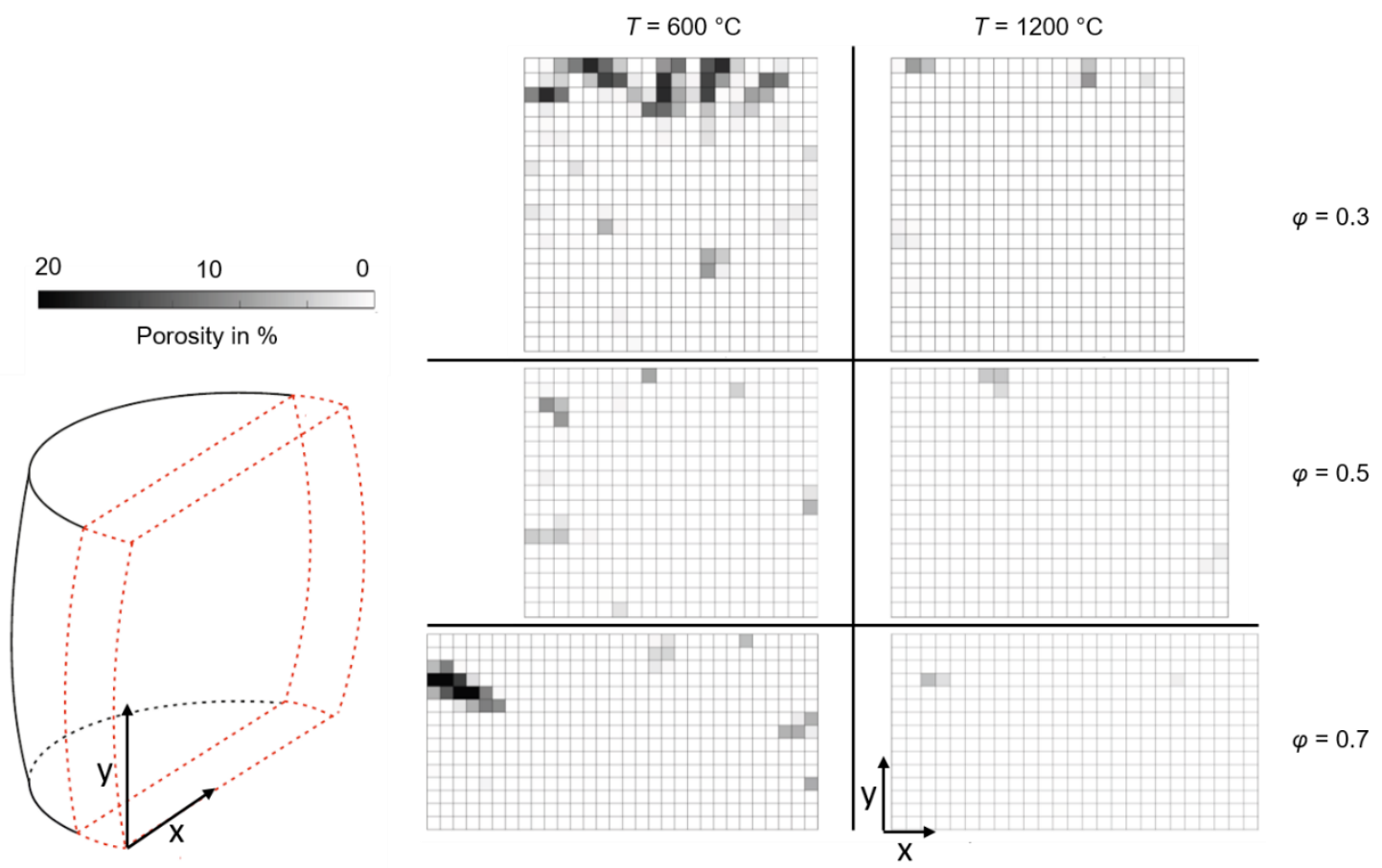

Figure 4 Mapping of the mean porosity values for each cast-forged variant
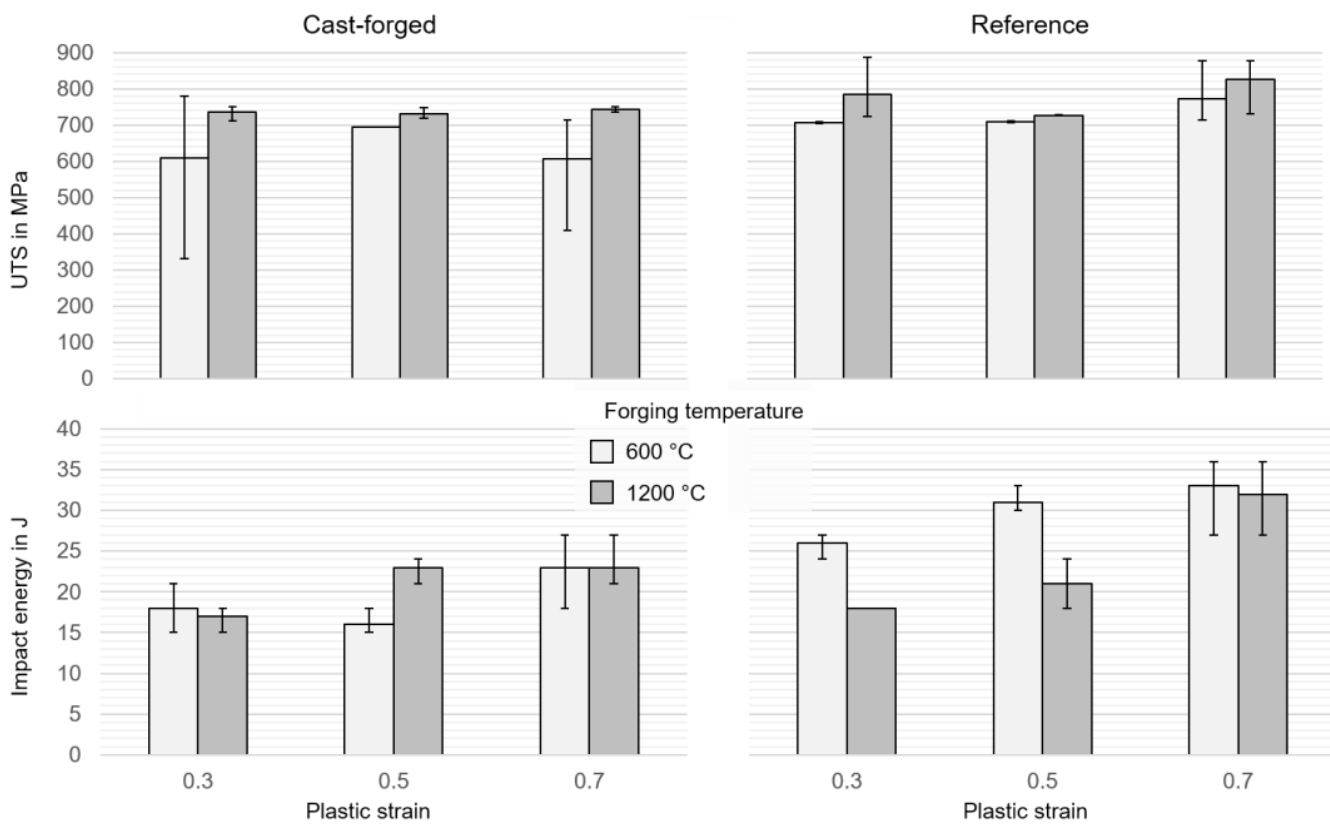

perature

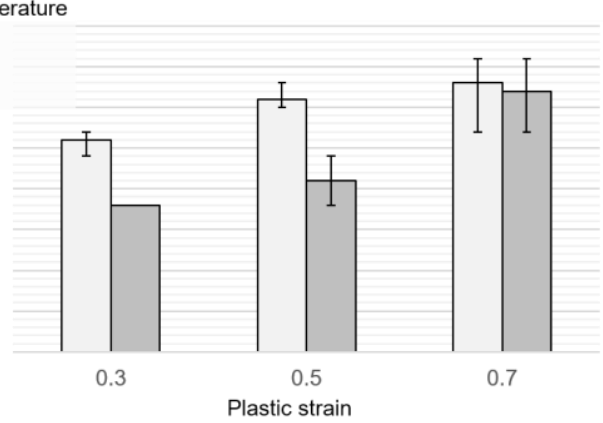

Figure 5 Results of the mechanical tests, error bars indicate minimum and maximum values 
The mechanical properties are summarised in Figure 5. The dominant factor with respect to the ultimate tensile strength (UTS) is the forging temperature. For both, the cast-forged and the reference material, UTS increases with higher forging temperatures. As expected, the influence of the plastic strain induced by forging on UTS is only minor. However, the impact energy of the cast-forged specimens does not seem to depend on the forging temperature, but increases with higher plastic strains. In contrast, the reference material shows a noticeable decrease in impact energy at higher forging temperatures and an increase with higher plastic strains.

In addition to these standardised specimens, smaller fracture specimens (DIN 50115) from horizontal and vertical orientations of the upset specimens were tested. The results show an anisotropy of the properties of the cast-forged $\left(\varphi=0.7, T=1200^{\circ} \mathrm{C}\right)$ material with a mean impact energy of $3.3( \pm 0.23) \mathrm{J}$ along the horizontal axis and $0.9( \pm 0.22) \mathrm{J}$ in vertical orientation. The reference specimens, which were extracted in the same way, show no significant anisotropy with and impact energy of $3.1( \pm 0.41) \mathrm{J}$ horizontally and $3.0( \pm 0.40) \mathrm{J}$ vertically.

Metallographic images of the polished and etched fracture specimen microstructures are displayed in Figure 6. There is a distinct difference in grain size between the coarser cast-forged and the reference microstructure. However, an increase in plastic deformation leads to a finer microstructure and the cast-forged microstructure with a plastic strain of $\varphi=0.7$ shows a grain size similar to that of the reference material after a plastic strain of $\varphi=0.3$. The forming temperature seems to have little influence on the ferritic-pearlitic microstructure after heat treatment.
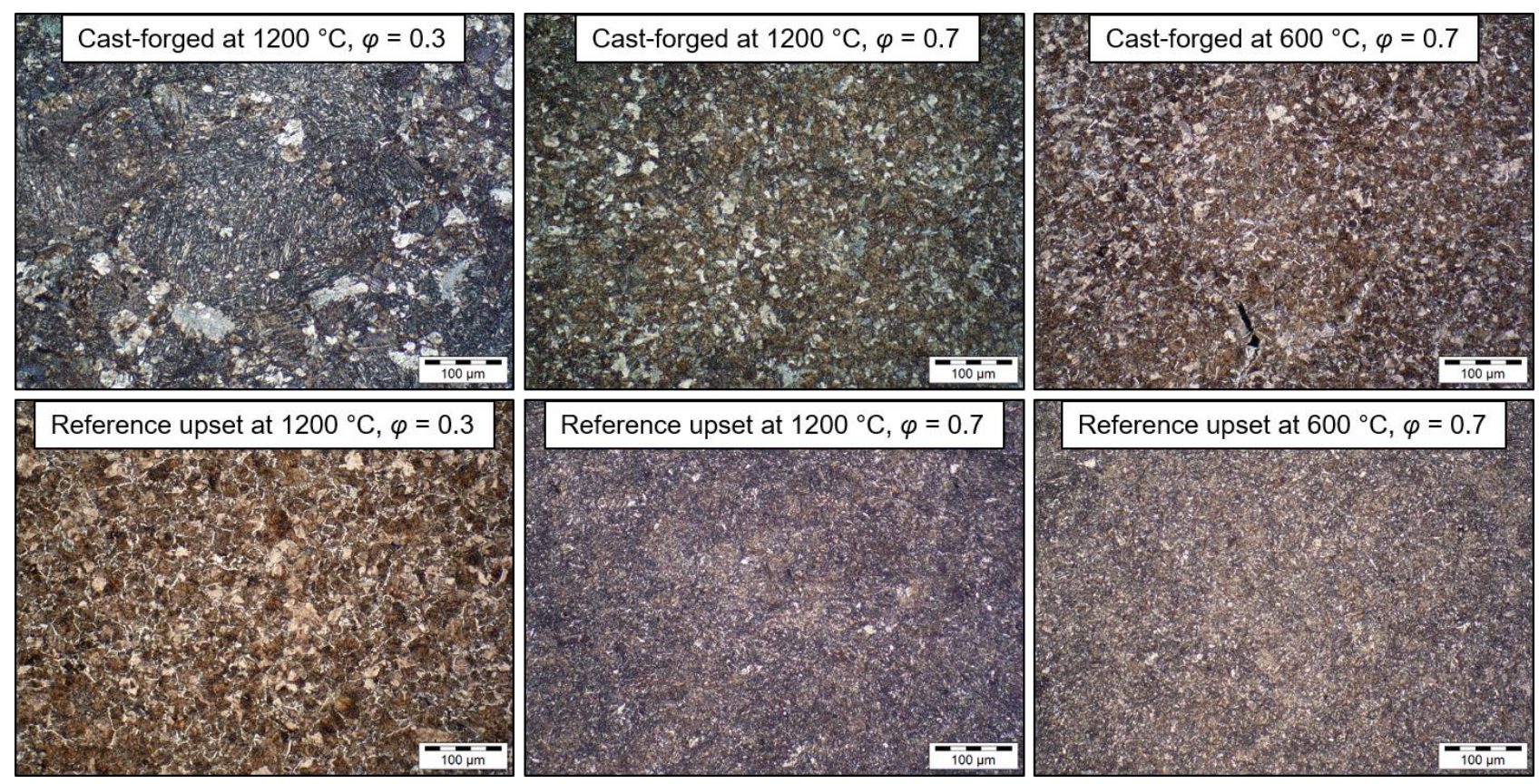

Figure 6 Metallographic images of the central zone of the upset specimens (+QT)

\section{DISCUSSION}

The results obtained in the present study demonstrate that the UTS of the cast-forged C45 material after heat treatment is close but still inferior $(5 \%)$ to the one of the reference material. The impact energy is significantly lower than that of the reference for most variants. To achieve the best mechanical properties, a high forming temperature and high plastic strains are beneficial. The mapping of the porosity (Figure 4) supports these findings. The central region of the specimens, which was mechanically tested, was found to be pore-free. This leads to the conclusion that the outer regions will possess material properties that should be below those of the one worst tested variant, as the plastic strain is low in these regions and macroscopic pores do persist. In comparison to a previous study concerning the cast-forging of low alloyed steel 42CrMo4 [6], the present 
results show the same general trends, with forming temperature influencing the UTS and plastic strain being the major factor on impact energy. In comparison, the impact energy of the cast-forged steel 42CrMo4 was higher than the one of the reference for all tested variants. These inexplicably high values hint at an effect of anisotropy due to compressed or elongated porosity [6]. In the present study, the existence of said anisotropy could be confirmed, as the C45 specimens showed distinct anisotropy.

\section{CONCLUSION}

Material properties close to those of the hot rolled reference material can be achieved after cast-forging of low alloyed and unalloyed steels. However, significant anisotropy may occur. This and the control of the plastic strain distribution have to be considered for the future design of cast-forging processes. Numerical simulations of the casting process allow predicting porous regions in the part and can serve as input for numerical forming simulations.

\section{ACKNOWLEDGEMENTS}

The present results were obtained in the research project "Precision Forging of Cast Preforms", Project number 351032371. The authors thank the German Research Foundation (DFG) for the financial support.

\section{REFERENCES}

[1] FEDERAL MINISTRY FOR ECONOMICS, AFFAIRS AND ENERGY. Lightweighting [online]. [viewed May 12, 2020]. Available from: https://www.bmwi.de/Redaktion/EN/Dossier/lightweighting.html.

[2] HEDICKE-CLAUS Y, LANGNER J, STONIS M, BEHRENS B-A. Innovative approach for planning efficient forging sequences. ZWF Zeitschrift fuer Wirtschaftlichen Fabrikbetrieb 2018, vol. 113, no. 10, pp. 668-672.

[3] PERRIER F, DESRAYAUD C, BOUVIER V. Microstructural and mechanical evolutions during the forging step of the COBAPRESS, a casting/forging process. In: ICAA13 Pittsburgh. Cham: Springer International Publishing, 2016, pp. 1691-1696.

[4] IBLEIB A, NEUBAUER A, PRIETZEL KO. Grundlegende Untersuchungen zum Gesenkschmieden in Kokille gegossener Ausgangsformen. Gießereitechnik 1980, vol. 26, no. 7, pp. 204-206.

[5] HARRIS N, SHAHRIARI D, JAHAZI M. Analysis of Void Closure during Open Die Forging Process of Large Size Steel Ingots. Key Engineering Materials 2016, vol. 716, pp. 579-585.

[6] URSINUS J, BONHAGE M, BÜDENBENDER C, NÜRNBERGER F, DEMLER E, BEHRENS B-A. Hot forming of cast steel cylinders. In: METAL 2019: 28th International Conference on Metallurgy and Materials. Ostrava: TANGER, pp. 501-506. 